\title{
The MAPKKKs Ste11 and Bck1 jointly transduce the high oxidative stress signal through the cell wall integrity MAP kinase pathway
}

\author{
Chunyan Jin", Stephen K. Kim, Stephen D. Willis and Katrina F. Cooper* \\ Department of Molecular Biology, Rowan University School of Osteopathic Medicine, Stratford, NJ, 08055 USA. \\ \# Current address: Shaoxing Women \& Children Hospital, 305 East Street, Shaoxing, Zhejiang, China, 312000. \\ * Corresponding Author: Katrina Cooper, Tel: +1 856566 2887; Fax: +1 856566 6366; E-mail: cooperka@rowan.edu
}

\begin{abstract}
Oxidative stress stimulates the Rho1 GTPase, which in turn induces the cell wall integrity (CWI) MAP kinase cascade. CWI activation promotes stress-responsive gene expression through activation of transcription factors (RIm1, SBF) and nuclear release and subsequent destruction of the repressor cyclin $\mathrm{C}$. This study reports that, in response to high hydrogen peroxide exposure, or in the presence of constitutively active Rho1, cyclin C still translocates to the cytoplasm and is degraded in cells lacking Bck1, the MAPKKK of the CWI pathway. However, in mutants defective for both Bck1 and Ste11, the MAPKKK from the high osmolarity, pseudohyphal and mating MAPK pathways, cyclin $C$ nuclear to cytoplasmic relocalization and destruction is prevented. Further analysis revealed that cyclin $\mathrm{C}$ goes from a diffuse nuclear signal to a terminal nucleolar localization in this double mutant. Live cell imaging confirmed that cyclin $\mathrm{C}$ transiently passes through the nucleolus prior to cytoplasmic entry in wild-type cells. Taken together with previous studies, these results indicate that under low levels of oxidative stress, Bck1 activation is sufficient to induce cyclin C translocation and degradation. However, higher stress conditions also stimulate Ste11, which reinforces the stress signal to cyclin $\mathrm{C}$ and other transcription factors. This model would provide a mechanism by which different stress levels can be sensed and interpreted by the cell.
\end{abstract}

\author{
doi: $10.15698 / \operatorname{mic} 2015.09 .226$ \\ Received originally: 06.05.2015; \\ in revised form: 05.08.2015, \\ Accepted 08.08.2015, \\ Published 07.09.2015.
}

Keywords: cyclin C, oxidative stress, protein degradation, programmed cell death, MAPK signal transduction pathways, mitochondrial

morphology.

\section{Abbreviations:}

CWI - cell wall integrity,

$I G$ - invasive growth,

HOG - high osmolarity glycerol,

MAPKs - mitogen activated kinase

cascades.

\section{INTRODUCTION}

A conserved survival instinct in all living cells is the ability to adapt to changes in their extracellular environment. To achieve this, cells convey information from a sensory input via a signaling cascade to the genes in charge of orchestrating the cellular response. Among the signaling pathways, the mitogen activated kinase cascades (MAPKs) are very well conserved from yeast to mammals (reviewed in [1]). Each MAPK cascade consists of a canonical module of three protein kinases, a MAP kinase kinase kinase (MAPKKK/MEKK), a MAP kinase kinase (MAPKK/MEK) and a MAP kinase (MAPK). In S. cerevisiae, there are five known MAPK cascades (reviewed in $[2,3]$ ) that control responses to different external signals stresses including nutrient starvation, high osmolarity, mating pheromone, and oxidative stress. Traditionally, the MAPK pathways have been depicted as insulated with each cascade being activated only in response to a particular extracellular signal. For example, the high osmolarity glycerol (HOG) pathway is predominantly (but not exclusively) activated in response to changes in osmolarity (reviewed in [4]), whereas the cell wall integrity (CWI) pathway is triggered by numerous stresses including cell wall deterioration, temperature shifts and oxidative stress (reviewed in $[5,6]$ ). More recently, it has been suggested that in situations where signal strength exceeds pathway capacity, there is a crosstalk between the pathways $[7,8]$.

Ste11 is a shared MAPKKK that plays an important role in transducing several signals. Ste11 transduces signals important for mating, invasive growth (IG, also known as pseudohyphal pathway) and resistance to high osmolarity, even though each pathway responds to different external stimuli and produces different outputs (see Figure 1). Ste11 is activated by the yeast homolog of the p21-like kinase 
(PAK) called Ste20 [9]. Dependent on the stimuli received, Ste11 phosphorylates a different MAPKK. How the cell determines which MAPKK to activate is only partially understood but thought to be dependent upon upstream components which route the signal to the appropriate MAPKK $[3,10]$. Over the last two decades, a principle has emerged involving scaffold proteins, which physically assemble MAPK modules, in directing which MAPK module is activated following a particular stress (reviewed in [11]). However, the Ste5 scaffold mediating the mating pathway (see Figure 1) was shown to function as a conformational switch to gate the flow of information between the mating and IG pathways [12]. These results indicate that the role scaffolds play in sorting MAPK signaling may be more complicated.

In addition to signaling in the HOG, IG and mating pathways, Ste11 is also required for the expression of FKS2 [13-15]. FSK2 encodes one of two alternate stress-induced catalytic subunits of the beta- 1,3 glucan synthase complex that is important for cell wall integrity under conditions of cell wall stress [16]. The role Ste11 plays in its activation is complex but it has been shown that its activation can be mediated by Ste11 cross talking with the mating, HOG, calcineurin and CWI pathways $[13,15]$. Thus, although the molecular mechanism by which this cross-talk is achieved is not well defined, it seems clear that Ste11 has functional redundancy with other MAPKK's [14, 15] (see Figure 1).

The CWI pathway is normally triggered by factors that evoke cell wall damage including oxidative stress (reviewed in [6]). The cell wall sensors signal through Rho1 to protein kinase $C[17,18]$ that in turn stimulates the CWI MAPK module. In brief, the stress signal flows from Pkc1 to Bck1 (MEKK), the redundant MEKs Mkk1 or Mkk2 (written hereafter Mkk1/2) to finally the Slt2/Mpk1 MAP kinase (see [6] for review). One readout of the CWI pathway is the activation of two transcription factors, RIm1 and SBF, which induce the expression of genes that remodel the cell wall [19-22]. RIm1 is activated by SIt2 mediated phosphorylation [20] whereas Slt2, and its pseudokinase paralogue $\mathrm{Kdx1}$, use a noncatalytic mechanism to activate SBF [23-25].

We have identified a third transcription factor called cyclin C that is regulated by the CWI pathway ([26-28] and reviewed in [29]). Unlike cyclins that regulate cell cycle progression, cyclin C and its cyclin dependent partner Cdk8, are conserved members of the Mediator complex associating with the RNA polymerase II holoenzyme (reviewed in [30]). Cyclin C-Cdk8 predominantly acts as a transcriptional

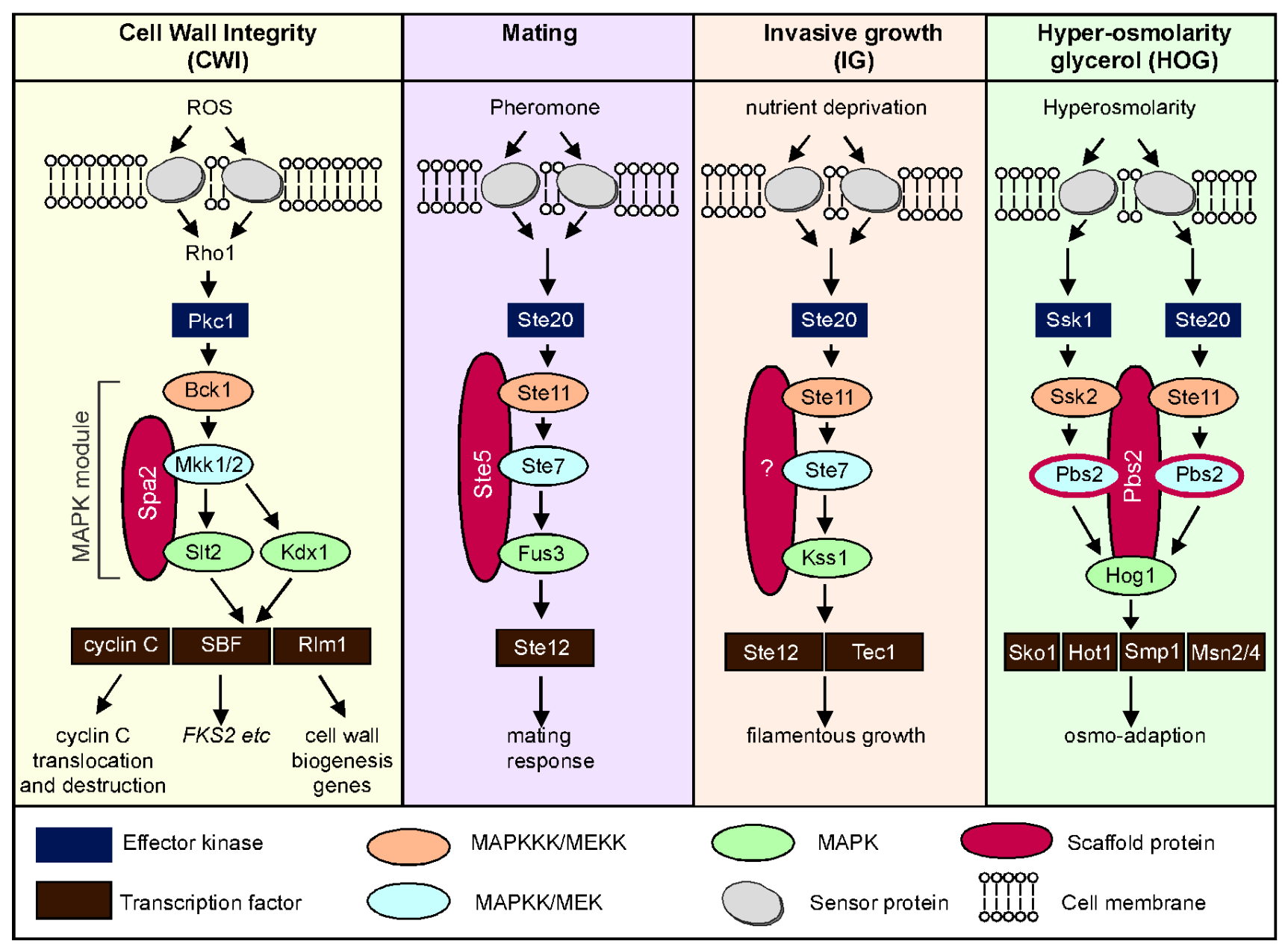

FIGURE 1: Schematic diagram of the MAPK modules of the cell wall integrity (CWI), mating, invasive growth (IG) and hyper-osmolarity glycerol (HOG) pathways in S. cerevisiae. 
repressor, regulating over 100 loci including many stress response genes [31, 32]. To relieve this repression, cyclin C, but not Cdk8, is translocated to the cytoplasm where it is consequently degraded in an ubiquitin dependent manner $[33,34]$. Importantly, before it is destroyed, cyclin C is required for stress-induced mitochondrial fission and programmed cell death [34, 35]. This cytoplasmic role of cyclin $\mathrm{C}$ in mediating mitochondrial fission and intrinsic apoptosis is conserved in mammals [36].

In this report, we show that under conditions of high oxidative stress, the capacity of the canonical CWI MAPK module is exceeded. In short, we provide evidence that Slt2 can be activated following high oxidative stress in the absence of Bck1. As a result, cyclin C is both translocated to the cytoplasm and degraded. This Bck1 independent translocation of cyclin $C$ requires Ste11. Furthermore, we provide evidence that the normal stress-induced path for $\mathrm{cy}$ clin $\mathrm{C}$ translocation starts in the nucleus, then transits to the nucleolus and finally enters the cytoplasm. We also show that CWI MAPK activity is only required for nucleoluscytoplasm translocation and not for the nuclear to nucleolus movement. These results suggest a mechanism by which high-stress conditions are recognized differently by the cell and transduced into changes in both gene expression and mitochondrial dynamics.

\section{RESULTS}

Bck1 is not required for MAPK mediated degradation of cyclin $\mathrm{C}$ under high stress

We have previously shown that the conserved CWI MAPK pathway transduces the oxidative stress signal from the cell wall sensors to induce cyclin C nuclear to cytoplasmic translocation and destruction [27]. In that report, a model was proposed in which the strength of the stress dictates which sensors are required. Here we examined whether the severity of the stress damage dictates the route the signal takes to trigger cyclin $\mathrm{C}$ relocalization.

To test this, we first examined whether the MEK kinase in the CWI pathway, Bck1, is required to transduce low and high oxidative stress signal to cyclin $C$. To address this question, we used functional cyclin C-myc and cyclin C-YFP reporters to examine cyclin $\mathrm{C}$ degradation kinetics and cytoplasmic localization, respectively. Consistent with our previously published work [26, 28, 34], Bck1 is required for cyclin $\mathrm{C}$ destruction and cytoplasmic relocalization of cyclin $\mathrm{C}$ following low oxidative stress $\left(0.4 \mathrm{mM} \mathrm{H}_{2} \mathrm{O}_{2}\right)$ exposure (Figure 2A, 2C and 2D). However, cyclin $\mathrm{C}$ destruction occurs with kinetics similar to wild type in a bck1 $\triangle$ mutant exposed to $1.2 \mathrm{mM} \mathrm{H}_{2} \mathrm{O}_{2}$ (Figure $2 \mathrm{~B}$, quantitated in Figure 2C). As anticipated from these results, we find that cyclin C-YFP forms cytoplasmic foci in the bck1 $\Delta$ mutant exposed to $1.2 \mathrm{mM} \mathrm{H}_{2} \mathrm{O}_{2}$ (Figure 2D, see Figure $2 \mathrm{E}$ for representative images). We also observed that cyclin $\mathrm{C}$ localization in $80 \%$ of $b c k 1 \Delta$ cells is both just outside of the nucleus in a
A

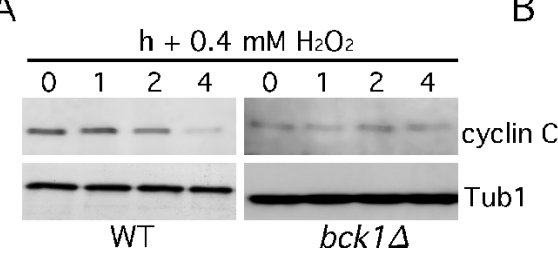

D

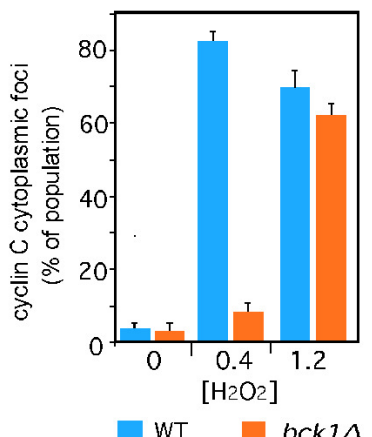

B

E
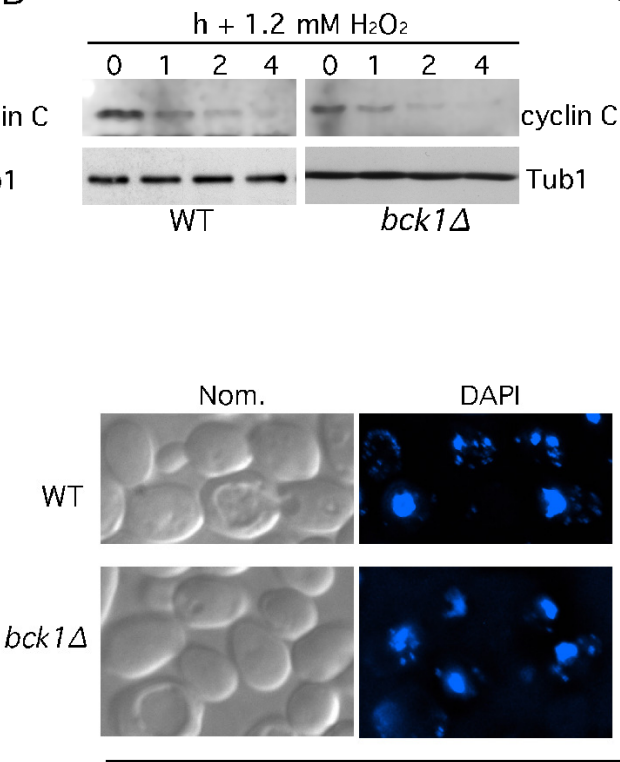

DAPI
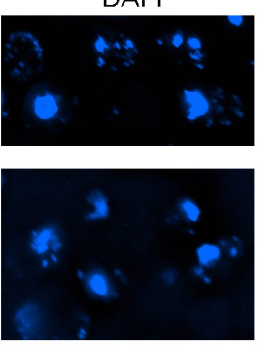

C

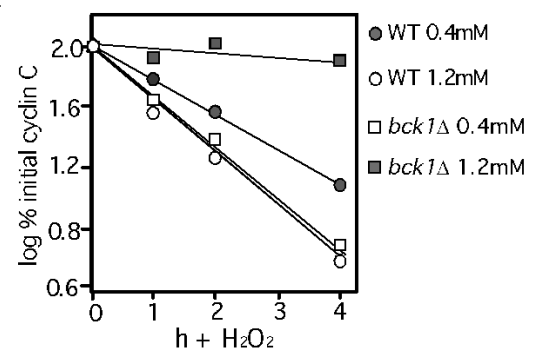

cyclin C-YFP
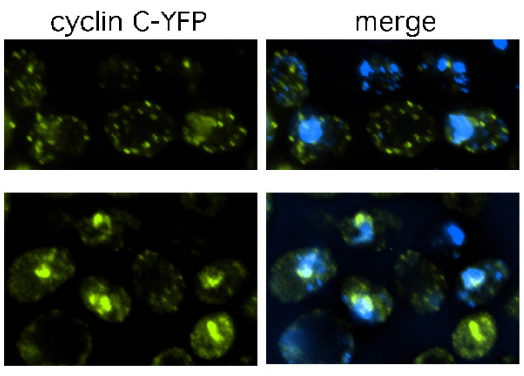

$2 \mathrm{~h}+1.2 \mathrm{mM} \mathrm{H}_{2} \mathrm{O}_{2}$

FIGURE 2: Bck1 is not required for cyclin $\mathrm{C}$ nuclear to cytoplasmic translocation and degradation following high (1.2 $\mathrm{mM}$ ) $\mathrm{H}_{2} \mathrm{O}_{2}$ stress. Wild type (RSY10) and bck1 (RSY1050) cultures expressing myc-cyclin C (pLR337) were grown to mid-log phase (0 h) then treated with 0.4 mM (A) or $1.2 \mathrm{mM}$ (B) $\mathrm{H}_{2} \mathrm{O}_{2}$ for the indicated times. Cyclin $\mathrm{C}$ levels were determined by Western blot analysis of immunoprecipitates. Tub1 levels were used as a loading control. (C) Quantification of the results obtained in (A) and (B). (D) The percent of cells (mean \pm s.e.m.) within the population displaying at least 3 cytoplasmic cyclin $\mathrm{C}$ foci is given before and following $\mathrm{H}_{2} \mathrm{O}_{2}(0.4$ and $1.2 \mathrm{mM})$ treatment for $2 \mathrm{~h}$. At least 200 cells were counted per time point from 3 individual isolates. (E) Representative images (collapsed de-convolved $2 \mu \mathrm{m}$ slices) of WT and $b c k 1 \Delta$ cells harboring cyclin C-YFP and after $2 \mathrm{~h} 1.2 \mathrm{mM} \mathrm{H}_{2} \mathrm{O}_{2}$ stress. 
perinuclear location as well as in the cytoplasm. This intermediate and cyclin $C$ localization phenotype (see images in Figure S1A) is however also observed in $28 \%$ of wild type cells after $2 \mathrm{~h}$ stress and this number decreases to $5 \%$ after $3 \mathrm{~h} \mathrm{H}_{2} \mathrm{O}_{2}$ stress. This suggests that the "intermediate phenotype" is a transient state in the kinetics of cyclin C export. Taken together these results indicate that an additional signaling pathway(s) is employed to transmit the oxidative stress signal when cells are exposed to elevated $\mathrm{H}_{2} \mathrm{O}_{2}$ concentrations.

Cyclin C destruction following high levels of oxidative stress requires both MAPKs of the CWI pathway

Both Slt2 and its pseudokinase $\mathrm{Kdx} 1$ mediate the export and degradation of cyclin $\mathrm{C}$ under conditions of low $\mathrm{H}_{2} \mathrm{O}_{2}$ stress [28]. The results described above indicate that a Bck1 independent pathway also transmits the high-stress signal to cyclin C. To determine whether downstream components of the CWI pathway are required for transducing the high-stress signal, cyclin $\mathrm{C}$ levels were monitored in a slt2 $2 k d \times 1 \Delta$ strain. These results show that cyclin $\mathrm{C}$ is stable following $1.2 \mathrm{mM} \mathrm{H}_{2} \mathrm{O}_{2}$ exposure whereas it is degraded in the single mutants albeit with slower kinetics (Figure 3A, quantitated in Figure 3B). As cyclin C is normally destroyed following its translocation to the cytoplasm, we monitored cyclin C-YFP localization in the s/t2 $k d x 1 \Delta$ strain subjected to $1.2 \mathrm{mM} \mathrm{H}_{2} \mathrm{O}_{2}$ treatment. Interestingly, fluorescence microscopy revealed that cyclin C-YFP did not form multiple cytoplasmic foci (Figure $3 \mathrm{C}$ and S1A). Rather, a single peri-nuclear focus was observed in most cells (quantitated in Figure 3D and see Figure S1B for field view). However, cyclin $C$ was exported in s/t2 $\Delta$ cells after treatment with $1.2 \mathrm{mM} \mathrm{H}_{2} \mathrm{O}_{2}$ (Figure $\mathrm{S} 1 \mathrm{C}$ and D). These results indicate that cyclin $\mathrm{C}$ is able to translocate from diffuse nuclear localization to a single peri-nuclear focus but was unable to enter the cytoplasm.

Cyclin C transits through nucleolus before it is exported into the cytoplasm

Our previous studies revealed that in oxidatively stressed cdk8 mutants, cyclin C-YFP formed a lone peri-nuclear focus that associated with the nucleolus [35]. In addition, Cdk8 also re-localized to the nucleolus in wild-type stressed cells but did not enter the cytoplasm [34]. These results led to the speculation that the normal stressinduced path for cyclin C starts in the nucleoplasm, then transits to the nucleolus and finally enters the cytoplasm. However, localization to the nucleolus was only observed in mutant cells raising the possibility that the nucleolar endpoint for cyclin $\mathrm{C}$ may not be the normal route in wild-
A

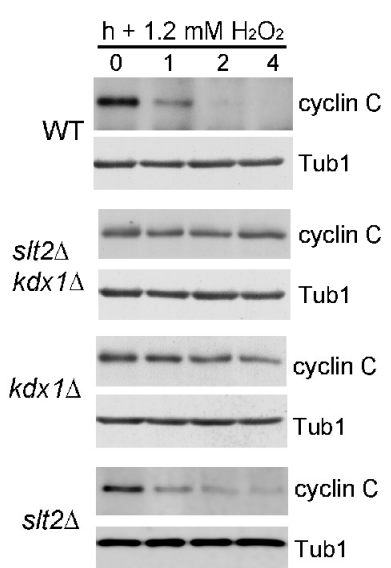

C

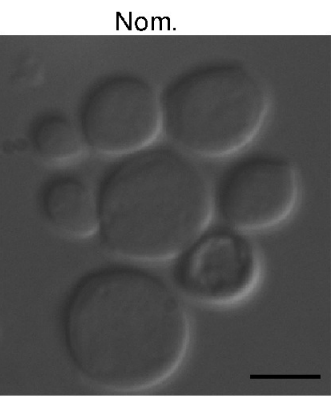

cyclin C-YFP/DAPI

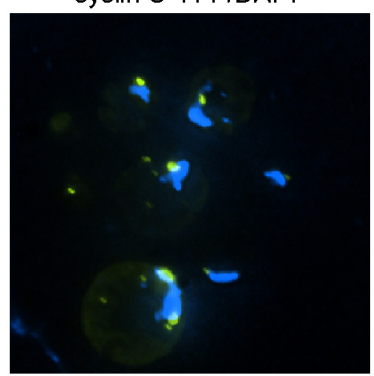

2h $1.2 \mathrm{mM} \mathrm{H} \mathrm{H}_{2} \mathrm{~s} / t 2 \Delta k d x 1 \Delta$
B

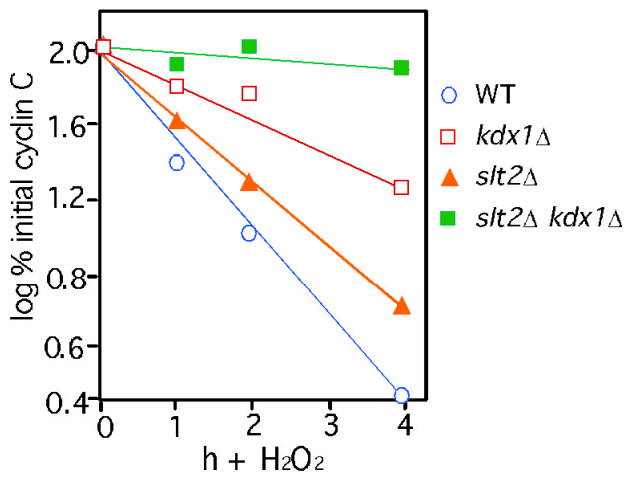

D

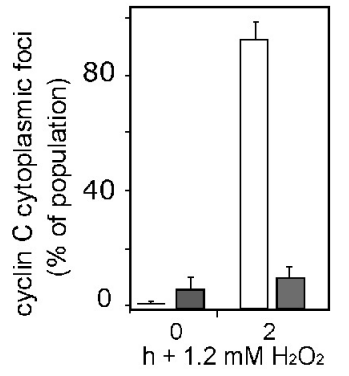

WT
FIGURE 3: Kdx1 and SIt2 promote cyclin $\mathrm{C}$ relocalization and destruction in response to $\mathbf{1 . 2}$ $\mathrm{mM} \mathrm{H}_{2} \mathrm{O}_{2}$ stress. (A) Cyclin $\mathrm{C}$ levels were monitored as described previously in wild type (RSY10), slt2 $\Delta k d x 1 \Delta$ (RSY1737), slt2 $\Delta$ (RSY1006) and $k d \times 1 \Delta$ (RSY1736) strains exposed to $1.2 \mathrm{mM} \mathrm{H}_{2} \mathrm{O}_{2}$ for the times indicated. Tub1 levels were used as a loading control. (B) Quantification of the results obtained in (A). (C) Cyclin C remains perinuclear in the slt $2 \Delta k d x 1 \Delta$ strain following $1.2 \mathrm{mM} \mathrm{H}_{2} \mathrm{O}_{2}$ stress. Fluorescence microscopy was conducted on mid-log phase on s/t2 $k d x 1 \Delta$ cells expressing YFP-cyclin $\mathrm{C}$ (pBK37) following (2 h) $1.2 \mathrm{mM} \mathrm{H}_{2} \mathrm{O}_{2}$ treatment. The cells were fixed, stained with DAPI and then examined by fluorescence microscopy. Representative images (collapsed deconvolved $0.2 \mu \mathrm{m}$ slices) of the results obtained are shown. (D) Quantification of the results in $C$. The percent of the population displaying at least 3 cyclin C-YFP foci in the cytoplasm is given (mean \pm s.e.m.). At least 200 cells were counted per time point from 3 individual isolates. 
type cells. To test this possibility, a wild-type culture expressing the nucleolar marker Nop1-CFP and cyclin C-YFP was grown to mid-log phase, harvested, then embedded in low temperature melting agarose containing $1.0 \mathrm{mM} \mathrm{H}_{2} \mathrm{O}_{2}$ (see Materials and methods for details). Images were collected immediately after the cells were immobilized in the agarose and every minute starting at $30 \mathrm{~min}$ for an additional $60 \mathrm{~min}$. As expected in unstressed cells, cyclin C-YFP displayed diffuse nuclear staining that may partially overlap with the Nop1-CFP signal (0 min time point, Figure 4A). However, at minute 53 , the cyclin C-YFP signal became more condensed and co-localized extensively with the nucleolar marker (bottom panels, Figure 4A). However, cyclin C-YFP co-localization with the nucleolus was transient, remaining nucleolar approximately seven minutes in this experiment before entry into the cytoplasm.

These results indicate that, in response to oxidative stress, cyclin C-Cdk8p normally transit to the nucleolus with only cyclin $\mathrm{C}$ continuing on to the cytoplasm. To further test this model, fixed wild-type cells harboring cyclin C-YFP and Nop1-RFP were examined 10, 20 and 60 minutes after treatment with $1.2 \mathrm{mM} \mathrm{H}_{2} \mathrm{O}_{2}$. After 10 minutes, a portion of cyclin $C$ can be seen in the nucleolus (Figure 4B, see Figure S2 for complete image of cell). Cyclin C-YFP and Nop1-RFP co-localization becomes more pronounced with time and after 60 minutes of stress most of cyclin $C$ has moved to the nucleolus. Taken together these results suggest a model in which cyclin C first transitions to the nucleolus before it is exported to the cytoplasm. However, the transient nature of cyclin C-nucleolar co-localization makes it difficult to capture this interaction for more detailed study.

Activated Rho1 signals cyclin C destruction through both CWI-dependent and independent pathways.

Our results indicate that exposure to high $\mathrm{H}_{2} \mathrm{O}_{2}$ concentrations leads to cyclin $\mathrm{C}$ destruction through both $\mathrm{CWI}-$ dependent and independent pathways. These results may indicate the existence of another pathway separate from the CWI system. Conversely, the CWI pathway itself may be modified in response to high stress conditions. To test
A
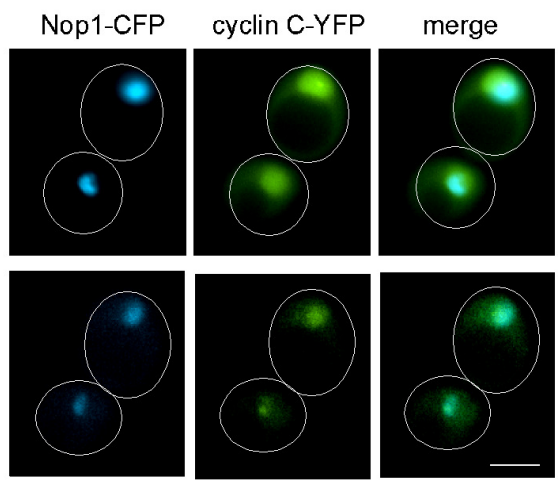

time in $\mathrm{min}$. $+\mathrm{H}_{2} \mathrm{O} 2$

$0^{\prime}$

$53^{\prime}$

B

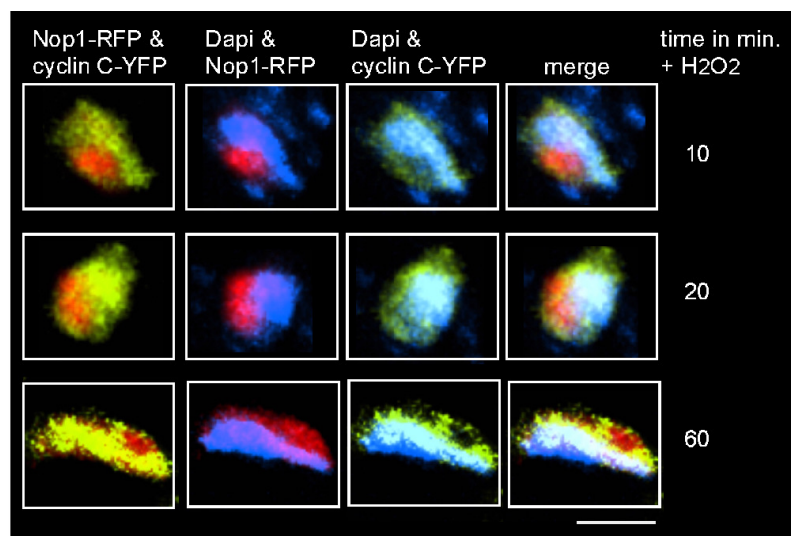

FIGURE 4: Cyclin $C$ transits through the nucleolus in response to stress. (A) Live cell imaging of immobilized wild type cells (FLY1589) expressing cyclin C-YFP and Nop1-CFP before (0 min) and following ( $53 \mathrm{~min}$ ) exposure to $1.0 \mathrm{mM} \mathrm{H}_{2} \mathrm{O}_{2}$. Arrows indicate restricted cyclin C-YFP signal coinciding with Nop1-CFP. (B) Enlarged fixed cell images of nucleus and surrounding area of wild type cells (RSY10) expressing cyclin C-YFP and Nop1-RFP. Cells were harvested and stained with DAPI following $1.2 \mathrm{mM} \mathrm{H}_{2} \mathrm{O}_{2}$ at the time points indicated.
A

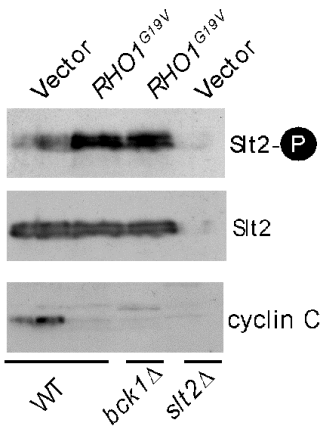

B

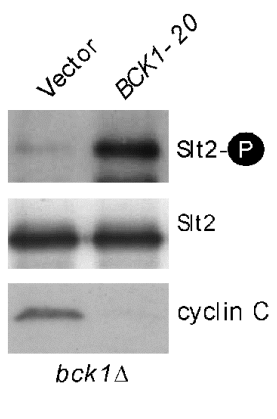

C

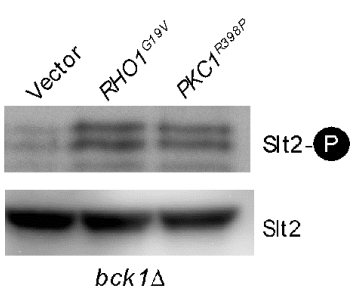

FIGURE 5: Bck1 is not required for Slt2 T-loop phosphorylation and cyclin $\mathrm{C}$ destruction following hyperactivation of the CWI pathway. (A) Slt2 T-loop phosphorylation (upper panel) was determined by Western blot analysis of protein extracts prepared from mid-log phase cultures (WT, RSY10, bck14, RSY1050, and s/t2 $\Delta$, RSY1057) expressing functional cyclin C-YFP (pBK37) and either $R H O 1^{G 19 V}$ or a vector control. The blot was stripped and re-probed for Slt2 and cyclin $\mathrm{C}$ protein levels (middle and lower panels respectively). (B) As in (A) except that Slt2 and cyclin $C$ were monitored in $b c k 1 \Delta$ cells expressing either a vector or a plasmid harboring a constitutively active $B C K 1$ allele (BCK1-20). (C) As in (A) except that Slt2 phosphorylation (top panel) was also monitored in $b c k 1 \triangle$ cells expressing a hyper-active allele of $P K C 1\left(P K C 1^{R 398 P}\right)$. 
these two models, we took advantage of previous studies demonstrating that cell wall stress induces sensor clustering [37] and enhanced Rho1 activation [38]. To genetically mimic this process, a constitutively activated $\mathrm{RHO}$ allele, $R H O 1^{G 19 V}$ [39], was utilized. Protein extracts were prepared from log-phase cultures and T-loop phosphorylation was used to monitor Slt2 activation. As a downstream readout for Slt2 activation, cyclin C levels were also monitored. The results revealed that Bck1 is not required for SIt2 activation or cyclin $C$ degradation in the presence of Rho $1^{\text {G19V }}$ (Figure $5 A)$. The $b c k 1 \triangle$ mutant was acting as expected as introduction of a hyperactive $B C K 1$ allele (BCK1-20 [40]) could efficiently induce Slt2 phosphorylation and trigger cyclin $C$ degradation (Figure 5B). Taken together, these results indicate that hyperactivated Rho1, either by mutation, or by enhanced sensor clustering through elevated $\mathrm{H}_{2} \mathrm{O}_{2}$ exposure, can transmit the stress signal to cyclin $\mathrm{C}$ through SIt2 in a Bck1-independent manner.

GTP-bound Rho1 has six known effectors in yeast (see [41] for review) including Pkc1 (see Figure 1). Pkc1 also transmits the oxidative stress signal to Slt2 [42]. As PKC1 is an essential gene [43], we monitored Slt2 T-loop phosphorylation in $b c k 1 \Delta$ cells expressing a constitutively active form of Pkc1 ( $\mathrm{PKC1}^{\mathrm{R} 398 \mathrm{P}}$ [43]). The results show that Slt2 is activated under these conditions (Figure $5 \mathrm{C}$ ). In addition, these findings suggest that Pkc1 is the effector molecule that mediates cyclin $\mathrm{C}$ degradation under conditions of high stress.

Activated Rho1p induces mitochondrial fission and promotes PCD through both cyclin C-dependent and independent pathways.

A previous study found that introduction of a constitutively active Rho1, but not Bck1, could largely restore the normal
$\mathrm{H}_{2} \mathrm{O}_{2}$-induced transcription program to cells deleted for the CWI pathway cell wall sensor Mtl1 $[39,44]$. These results suggested to these authors that Mtl1 signals through Rho1 but not downstream components of the CWI pathway. We previously demonstrated that $\mathrm{Mtl} 1$ and the $\mathrm{CWI}$ signaling are required for normal cyclin $\mathrm{C}$ nuclear release and subsequent mitochondrial fragmentation $[27,28]$. Therefore, we tested whether activated Rho1 alone was sufficient to regulate cyclin $C$ translocation in the absence of additional stress signals. To address this question, we examined mitochondrial morphology by fluorescence microscopy in cells expressing either Rho $1^{\mathrm{G} 19 \mathrm{~V}}$ or a vector control. This experiment revealed that mitochondria were significantly more fragmented in cells expressing Rho $1^{\mathrm{G} 19 \mathrm{~V}}$ than the vector control (Figure 6A, quantitated in 6B). These results indicate that Rhol signaling is sufficient to induce mitochondrial fragmentation. To determine if this phenotype is dependent on cyclin $C$, this experiment was repeated in a cnc1 $1 \Delta$ strain. In the absence of cyclin $\mathrm{C}$, mitochondrial fragmentation was significantly reduced in cells expressing Rho $1^{\text {G19v }}$ compared to control. However, mitochondrial fragmentation was still observed above vector controls in the cnc1 $\Delta$ strain indicating that Rho1 signaling is able to induce mitochondrial fragmentation in both cyclin $\mathrm{C}$ dependent and independent mechanisms.

We have previously demonstrated that activation of the CWI MAPK pathway using activated Rho1 is translated by the cells as a high stress situation [27, 28]. Therefore we addressed if the Rho $1^{\mathrm{G} 1 \mathrm{~V} V}$ mediated mitochondria fragmentation seen is dependent upon Bck1. The results (Figure 6C and quantitated in $6 \mathrm{D}$ ) show that this is indeed the case with over $60 \%$ of $b c k 1 \Delta$ cells harboring Rho $1^{\text {G19v }}$ showing cyclin $\mathrm{C}$ dependent mitochondrial fission compared to $\sim 10 \%$ of the cells harboring a vector control. These results
A

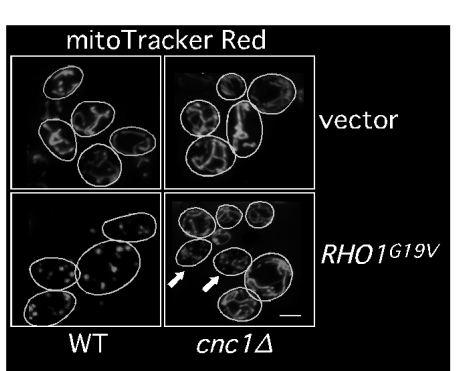

C

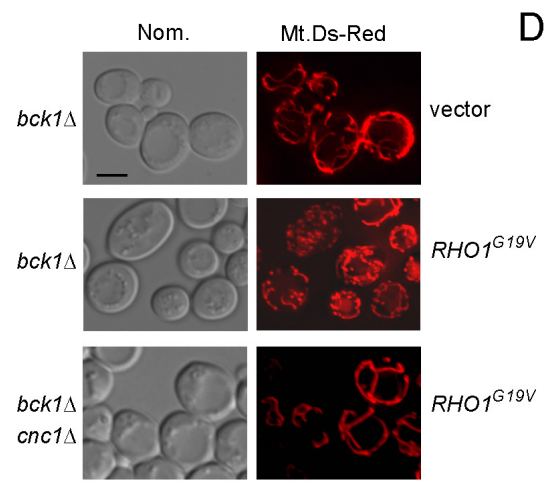

B
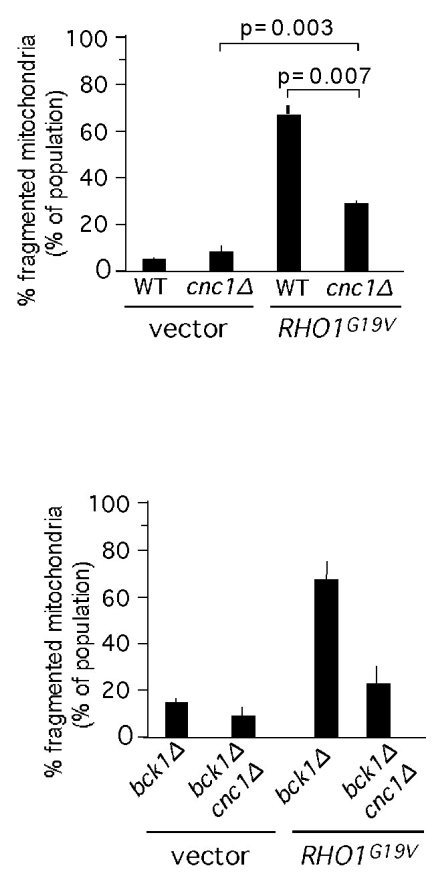

FIGURE 6: $R$ HO1 ${ }^{\text {G19V }}$ promotes cyclin C-dependent mitochondrial fission and programmed cell death in the absence of stress. (A) Mitochondrial morphology was followed by fluorescence microscopy in wild type (RSY10) and cnc1s (RSY391) cultures expressing $\mathrm{mt}$-dsRed and either a vector control or $\mathrm{RHO}^{\mathrm{G19V}}$. Representative images ( $0.2 \mu \mathrm{m}$ slices) of each cell type are shown. The arrows indicate cells exhibiting fission in the $c n c 1 \Delta$ mutant. (B) Quantitation of three independent isolates exhibiting reticular or fragmented mitochondria were determined from $\geq 600$ cells per culture (mean \pm s.e.m.) $p$ values for then indicated data sets are shown. (C) Mitochondrial morphology was fol-

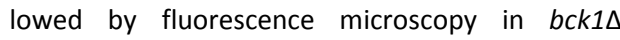

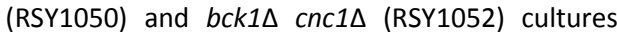
expressing mt-dsRed and either a vector control or $R H O 1^{G 19 V}$ (D) Quantitation of three independent isolates exhibiting reticular or fragmented mitochondria were determined from $\geq 600$ cells per culture. 
support the model that, under conditions of high stress, the stress signal can reach cyclin C independent of Bck1.

\section{Rho1-dependent cyclin C translocation induces oxidative stress hyper-sensitivity.}

Extensive mitochondrial fission is an early cytological landmark in PCD initiation, although fragmentation itself does not insure cell death [45]. We have previously demonstrated that precocious release of cyclin $C$ from the nucleus caused mitochondrial fission in the absence of stress and sensitized cells to $\mathrm{H}_{2} \mathrm{O}_{2}$ [46]. To determine whether Rho1-dependent cyclin $\mathrm{C}$ translocation also induced oxidative stress hyper-sensitivity, we monitored the viability of $b c k 1 \Delta$ cells following treatment with $1.2 \mathrm{mM}$ $\mathrm{H}_{2} \mathrm{O}_{2}$. As expected from our earlier results, loss of Bck1 activity did not alter the stress sensitivity compared to wild type (Figure 7A). This loss of viability was dependent on cyclin $\mathrm{C}$ as the $b c k 1 \Delta$ cnc1 $\Delta$ double mutant displayed resistance to $\mathrm{H}_{2} \mathrm{O}_{2}$. To determine whether the cell death observed on the plates were due to $P C D$, the strains just described were treated with $\mathrm{H}_{2} \mathrm{O}_{2}$ and PCD execution was measured by TUNEL assays. These experiments indicated that, similar to mitochondrial fission, activated Rho1 increased $\mathrm{H}_{2} \mathrm{O}_{2}$ sensitivity that was partially dependent on cyclin C (Figure 7B).

To understand the nature of this additional signal, the percentage of the population exhibiting high ROS concentrations was determined by DHE staining and fluorescence activated cell analysis. DHE oxidation measures internal
ROS levels that can be elevated by damaged mitochondria and elevated DHE oxidation is casually related to the cell's likelihood to induce PCD. The results indicated that the presence of Rho1 ${ }^{\mathrm{G} 19 \mathrm{~V}}$ did not induce elevated ROS levels under normal growth conditions but the percent of the population of DHE positive cells increased following $\mathrm{H}_{2} \mathrm{O}_{2}$ treatment (Figure $7 \mathrm{C}$ ). As observed with the TUNEL assays, much, but not all, of the increase in DHE positive cells is dependent on cyclin C. The cyclin C-independent ROS increase may be the result of continued mitochondrial fragmentation through another Rho1-dependent signaling pathway (see discussion).

The partial requirement of cyclin $\mathrm{C}$ for $\mathrm{Rho} 1^{\mathrm{G} 19 \mathrm{~V}}$. dependent mitochondrial fission, $\mathrm{H}_{2} \mathrm{O}_{2}$-induced $P C D$ and elevated internal ROS levels could be due to its transcriptional regulatory role, its mitochondrial function, or both. Given its reduced overall levels in cells expressing activated Rho1, we first asked whether cyclin C was still functioning as a transcription factor. Cyclin $C$ represses the transcription of both stress response [33] and early meiotic genes (e.g., SPO13) [47] during mitotic cell division. Therefore, wild type and cnc1 $\Delta$ strains were transformed with plasmids expressing either $\mathrm{RHO}^{\mathrm{G1}}{ }^{\mathrm{V} V}$ or a vector control and a spo13-lacZ reporter gene. Using a plate assay to monitor ßgalactosidase activity, this experiment revealed that cyclin C still repressed spo13-lacZ transcription even in the presence of Rho ${ }^{\mathrm{G1} 19 \mathrm{~V}}$ (Figure 7D). These results indicate that although cyclin C levels are reduced, it must still pass through the nucleus with sufficient retention to repress
A

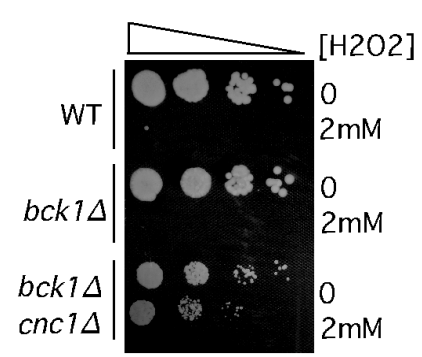

C

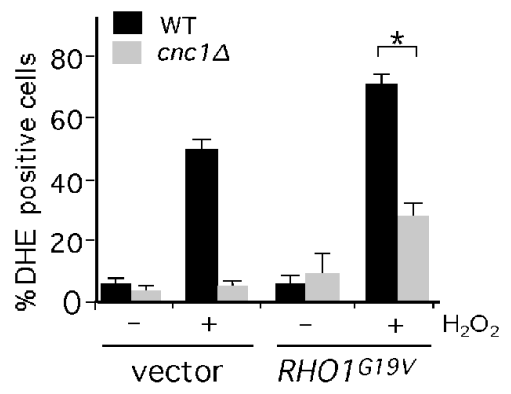

B

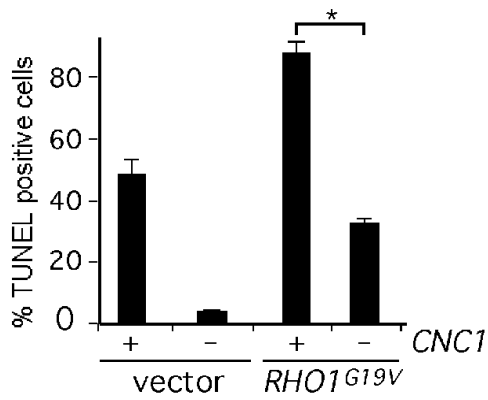

D

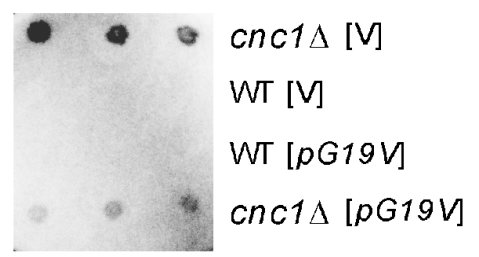

FIGURE 7: RHO1 $^{\text {G19V }}$ promotes cyclin Cdependent programmed cell death in the absence of stress. (A) Cell viability assays on wild type (RSY10), bck1 (RSY1050)

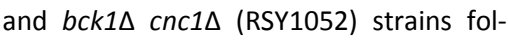
lowing treatment with $2 \mathrm{mM} \mathrm{H}_{2} \mathrm{O}_{2}$ for $2 \mathrm{~h}$. Decreasing dilutions of the cells (represented by the arrow) were plated on YPDA media and the surviving colonies photographed after 2 days at $30^{\circ} \mathrm{C}$. (B) Strains wild type (RSY10) and cnc1 (RSY391) cultures expressing mt-dsRed and either a vector control or $\mathrm{RHO}^{\mathrm{G} 19 \mathrm{~V}}$ were treated with $2 \mathrm{mM} \mathrm{H}_{2} \mathrm{O}_{2}$ for $20 \mathrm{~h}$ then assayed for double stranded breaks using TUNEL assays. The percent of TUNEL positive cells is given (mean \pm s.e.m.). In all panels, the asterisk indicate $p<0.05$ (Student's $T$ test). (C) Strains described in (A) were treated with $2 \mathrm{mM}$ $\mathrm{H}_{2} \mathrm{O}_{2}$ for $20 \mathrm{~h}$ and the percent of the population positive for DHE oxidation is shown (mean \pm s.e.m.). (D) Cyclin C represses transcription in Rho1 hyperactivated strains. The aberrant vegetative expression of the meiosis-specific spo13lacZ reporter gene (p42513Z) was analyzed in wild type (RSY10) and cnc1 (RSY391) strains harboring a vector control (V) or hyperactive $R H O 1^{G 19 V}$ allele. Three independent transformants were assayed on plates for ß-galactosidase expression by cleavage of the substrate 5-bromo-4-chloro-3-indolyl-ß-Dgalactopyranoside (X-gal). 
SPO13 transcription. In addition, these findings suggest that the role cyclin C plays in enhancing the activated Rho1 phenotypes can occur through its transcriptional and/or mitochondrial role (see Discussion).

\section{Ste11 is required for cyclin $\mathrm{C}$ mitochondrial relocalization} and destruction in response to high $\mathrm{H}_{2} \mathrm{O}_{2}$ induced stress. Previous studies revealed a genetic interaction between the CWI pathway and Ste11 function. Specifically, these studies found that a ste $11 \Delta$ bck1 $1 \Delta$ double mutant displayed synthetic defects in cell wall integrity and that Slt2 is required for Ste11-dependent regulation of FKS2 [14, 15]. To test whether Ste11 played a role in cyclin $C$ destruction in response to high $\mathrm{H}_{2} \mathrm{O}_{2}$ treatment, a ste $11 \Delta$ and a bck1 $\Delta$ ste11 1 strain was constructed expressing myc-cyclin C. A time-course experiment revealed that cyclin $C$ was protected from destruction in the double mutant whereas it was destroyed with similar kinetics to wild type cells in ste $11 \Delta$ (Figure $8 \mathrm{~A}$, quantitated in $8 \mathrm{~B}$ ). Next, cyclin $\mathrm{C}$ localization was monitored under high $\mathrm{H}_{2} \mathrm{O}_{2}$ conditions. A ste11 single mutant or the $b c k 1 \Delta$ ste11 $1 \Delta$ double mutant was transformed with the cyclin C-YFP expression plasmid. In the absence of stress, cyclin C-YFP exhibited a diffuse nuclear signal in both strains similar to wild type (Figure $8 \mathrm{C}$ ).
In the ste $11 \Delta$ mutant, exposure to high $\mathrm{H}_{2} \mathrm{O}_{2}$ concentrations resulted in cells displaying either cytoplasmic (light green arrows) or large peri-nuclear foci (red arrows). These results indicate that Ste11 is not essential for cyclin C relocalization but appears necessary for high efficiency translocation. In the double mutant, a higher percentage of the population exhibited a large focus associated with the nucleus and fewer cytoplasmic foci (Figure 8C, quantified in Figure $8 \mathrm{D}$ and see Figure S2 for field view of cells). These results indicate that Ste11 and Bck1 play partially redundant roles in directing cyclin $\mathrm{C}$ from the nucleolus to the cytoplasm in response to high $\mathrm{H}_{2} \mathrm{O}_{2}$ treatment.

\section{DISCUSSION}

Cyclin C and its kinase Cdk8 are components of the RNA polymerase II associated Mediator complex. This kinase functions primarily as a transcriptional repressor and targets a variety of genes most frequently those involved in the stress response. In response to stress, this repression is removed by nuclear to cytoplasmic relocalization of cyclin C. Previous studies found that the MAPKKK component of the CWI pathway (Bck1) is essential to trigger cyclin C relocalization in response to low-level $\mathrm{H}_{2} \mathrm{O}_{2}$ exposure. This report extends these observations by demonstrating that, in
A

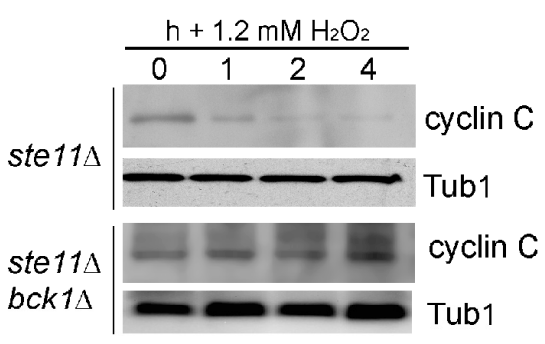

C
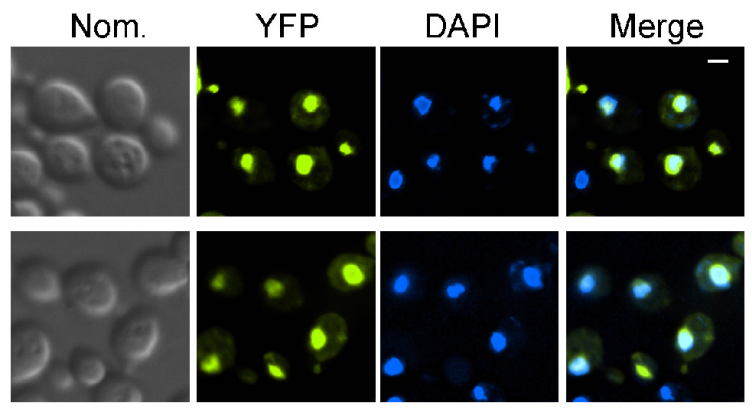

control
B

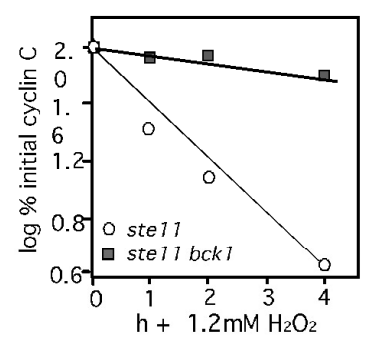

D

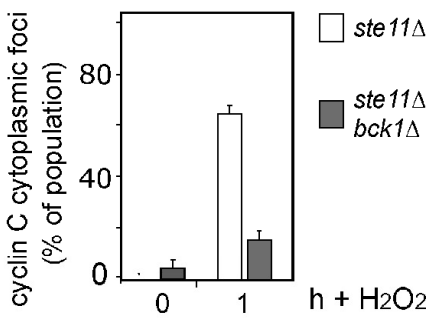

FIGURE 8: Ste11 is functionally redundant with Bck1 following $1.2 \mathbf{m M ~ H}_{2} \mathrm{O}_{2}$ stress. (A) Myc-cyclin $\mathrm{C}$ levels were monitored as described previously in ste $11 \Delta$ (RSY1983) and ste11 $b c k 1 \Delta$ strain (RSY1985) exposed to $1.2 \mathrm{mM} \mathrm{H}_{2} \mathrm{O}_{2}$ for the times indicated. Tub1 levels were used as a loading control. (B) Quantification of the results obtained in (A). (C) Ste11 is required for normal cyclin $\mathrm{C}$ nuclear release following $1.2 \mathrm{mM}$

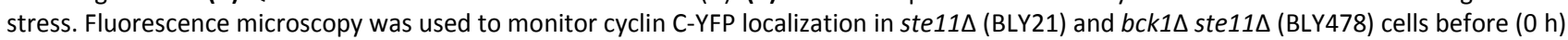
and following $(2 \mathrm{~h}) 1.2 \mathrm{mM} \mathrm{H} \mathrm{O}_{2}$ treatment. Representative images (collapsed de-convolved $0.2 \mu \mathrm{m}$ slices) of the results obtained are shown. Perinuclear and cytoplasmic localization of cyclin C-YFP are indicated by the red and yellow arrows, respectively. (D) Quantification of the results in (C). The percent of the population displaying at least 3 cyclin C-YFP foci in the cytoplasm is given (mean \pm s.e.m.). At least 200 cells were counted per time point from 3 individual isolates. 
response to either high $\mathrm{H}_{2} \mathrm{O}_{2}$ concentrations or in the presence of the constitutively active Rho1, Bck1 activity is combined with that of Ste11, the MAPKKK normally associated with mating type, pseudohyphal or high osmolarity environmental signaling. With respect to the cyclin $\mathrm{C}$ relocalization pathway, this study found that Ste11 and Bck1 are required for cyclin $C$ translocation from the nucleolus to the cytoplasm. Taken together, these results revealed a mechanism by which the cell can distinguish low from high oxidative stress conditions by Ste11 activation. In addition, these results demonstrate a regulated step in the cyclin $C$ relocalization pathway from the nucleolus to the cytoplasm.

MAP kinase signaling pathways are designed to recognize specific stimuli then transduce that signal to the nucleus to alter the transcription program. To achieve this goal, four general mechanisms (docking interactions, scaffold proteins, cross pathway inhibition and kinetic insulation) are in place to insulate the activation of one pathway from another (reviewed in [8]). However, recent studies have revealed an increasing important role for allowing MAP kinase pathway crosstalk. For example, in response to zymolyase cell wall stress, the sensors of the HOG pathway are required to upregulate genes controlled by the CWI MAPK module $([48,49]$ and reviewed in [50]). Likewise, in strains deleted for either Pbs2 (MAPKK and scaffold) or Hog1 (see Figure 1), stimulation with high osmolarity stress results in crosstalk to the mating response [51]. These observations are consistent with the hypothesis of Murray and colleagues who posited that connectivity between different MAPK signaling pathways allows for multiple input sensing and decision making [52].

In this report, we identified a lateral signaling mechanism for the cell wall integrity (CWI) pathway that is activated in response to excessive oxidative stress. Specifically, Ste11 is required for normal degradation and cytoplasmic relocalization of cyclin $\mathrm{C}$ in response to high stress conditions (see Figure 9). The genetic, cellular and biochemical results presented here suggest that mechanistically this is achieved by Ste11 activating Mkk1/2. Mkk1/2 in turn activates SIt2 and $K d x 1$, an event that is required for cyclin $C$ translocation [28]. Importantly, to date the redundant Mkks are the only reported MAPKKs that can transfer the activated phosphate group to Stl2 and Kdx1 (reviewed in [6]). Previous studies have also reported functional redundancy between Ste11 and Bck1 with regards to the activation of FSK2 following stress [14]. Interestingly, Mkk1/2 is not the only kinase that Ste11 activates under high oxidative stress. Tyrosine phosphorylation of Hog1 has been observed following treatment of cells with $3 \mathrm{mM} \mathrm{H}_{2} \mathrm{O}_{2}$ [53]. Similarly, by using expression quantitative trait loci (eQTL) studies, Wang et al. proposed that Ste11 may also regulate the $\mathrm{Pbs} 2-\mathrm{Hog} 1$ signaling pathway under oxidative stress [54]. However, it is unlikely that $\mathrm{H}_{2} \mathrm{O}_{2}$ induced activation of Hog1 is required for cyclin $\mathrm{C}$ translocation to the cytoplasm as cyclin $\mathrm{C}$ is degraded in response to low $\mathrm{H}_{2} \mathrm{O}_{2}$ stress in hog $1 \Delta$ cells [55].

One unanswered question that has arisen from this work is how the stress signal is transmitted to Ste11 following high $\mathrm{H}_{2} \mathrm{O}_{2}$ stress (blue arrows, Figure 9). Our previous

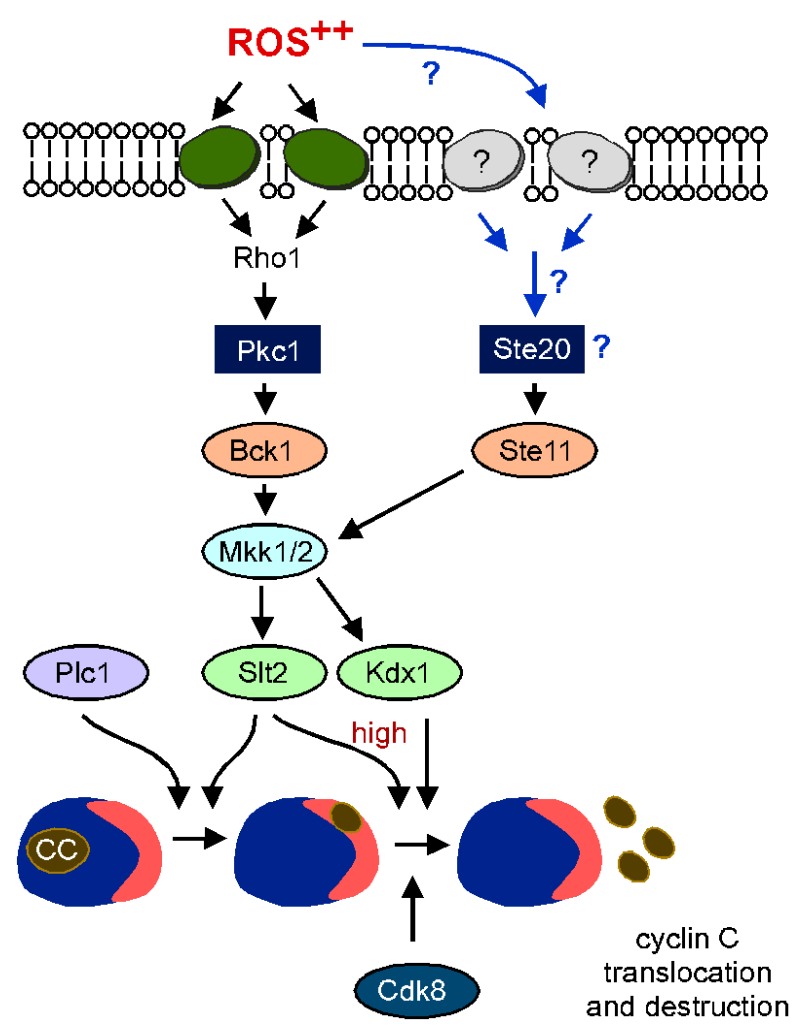

FIGURE 9: Proposed model for stress-activated signal transduction pathways mediating cyclin $\mathrm{C}$ nuclear export and destruction following high oxidative stress. Following high ROS stress cyclin C moves first to the nucleolus and then to the cytoplasm. Movement to the nucleolus requires Plc1 [55] whereas nucleolar export requires Slt2, Kdx1 activation and Cdk8 function [28, 34]. Under mild ROS stress the canonical CWI pathway is sufficient to transmit the stress signal to cyclin C leading to its nuclear export and destruction [28]. Under elevated ROS stress an additional MEKK (Ste11) is also required to transmit the stress signal via Mkk1/2 to cyclin C. Other sensors may also feed into the Ste11-Mkk1/2 pathway (see discussion for details).

work has suggested that additional cell wall sensors are activated in response to high stress [27]. One strong possibility is that similar to zymolyase stress, the sensors from the HOG pathway, SIn1 and/or Sho1, may transmit the oxidative stress signal to Ste11. Consistent with this, it has been reported that Ste11 can bind directly to the cytoplasmic tail of Sho1 [56] although it is not clear how this interaction directs kinase activation. Also, in support of this model is the observation that in pathogenic fungi Aspergillus fumigatus [57] and Candida albicans [58]), both Sho1 and $\operatorname{SIn} 1$ are cell wall sensors for environmental oxidative stress [59]. Consistent with the notion that both sensor proteins play a role, deletion of SHO1 in the bck1S strain resulted in an "intermediate" phenotype with respect to cyclin C nuclear export and degradation (Figure S3). In other words, cyclin $\mathrm{C}$ was partially stabilized in the $b c k 1 \Delta$ sho1 $\Delta$ strain and was exported but not as robustly as in the sho1 $\Delta$ mutant alone. However, the double mutant did not protect cells from dying following treatment with $\mathrm{H}_{2} \mathrm{O}_{2}$. 
The nucleolus is the site of rRNA transcription and ribosome assembly. In response to many stressors including oxidative stress, rRNA transcription and ribosome assembly is halted. For example, the RNA polymerase I transcription factor Rrn3, relocalizes from the nucleolus to the cytoplasm to inhibit transcription following cellular damage [60]. In mammalian cells, the Rrn3 homolog TIF-1A is also inhibited in response to stress through phosphorylation by the stress activated Jnk MAPK [61]. This report demonstrated that cyclin $C$ transits through the nucleolus in response to oxidative stress prior to its translocation to the cytoplasm. We have previously found that Cdk8 also exhibits a change from diffuse nuclear to the nucleolus following $\mathrm{H}_{2} \mathrm{O}_{2}$ treatment [34]. These results raise the possibility that cyclin C-Cdk8 performs a regulatory role in the stressed nucleolus. No target of cyclin C-Cdk8 in the RNA Pol I machinery has been identified but this kinase has been shown to modify components of the RNA Pol II Mediator complex, transcription factors and chromatin binding proteins [62]. Therefore, a role for cyclin C-Cdk8 in down regulating Pol I would not be surprising.

This study and previous reports [27, 28, 34, 35, 46] have begun to define the pathway that governs cyclin $C$ translocation. Under normal conditions, cyclin $\mathrm{C}$ resides in the nucleoplasm as expected for a transcription factor (Figure 9). In response to stress, cyclin $C$ relocalizes to the nucleolus through a process that requires Phospholipase $C$ (PIc1) and a cis-acting element (A110) on the cyclin itself
[34]. In addition, under low stress conditions, Slt2 is also required for this step and does so by directly phosphorylating cyclin $\mathrm{C}$ [28]. Increasing $\mathrm{H}_{2} \mathrm{O}_{2}$ concentrations or the presence of activated Rho1 relieves this requirement. Once cyclin $C$ reaches the nucleolus, the combined activity of Cdk8 [35], Bck1 and Ste11 (this report) are necessary for efficient translocation to the cytoplasm where it interacts with the mitochondria. Taken together, these studies define a complicated, multi-step switch that controls subcellular cyclin C localization. However, it is important to note the consequences to the cell if cyclin $\mathrm{C}$ is mis-localized. For example, deleting CNC1 results in no cytoplasmic cyclin C and significant protection from oxidative stress-induced PCD [26]. Conversely, loss of Med13, the nuclear anchor for cyclin C, allows continuous nuclear release of cyclin C resulting in constitutive mitochondrial fragmentation and hyper-sensitivity to oxidative stress [46]. Therefore, the cell must possess a responsive, interactive system to precisely control cyclin C subcellular localization.

\section{MATERIALS AND METHODS \\ Yeast strains and plasmids}

The haploid strains used in this study are listed in Table 1 and derived from RSY10, an ade6 derivative of W303-1A [47].

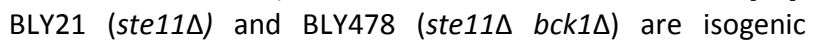
W3031-A strains except that ade3-1 is mutated instead of ade6. FLY1589 was a gift from F. Luca and is a diploid strain with integrated Nop1-CFP::KANMX6. BCK1 was deleted from

TABLE 1. Yeast strains used in this study.

\begin{tabular}{|c|c|c|}
\hline Strain & Genotype & Source \\
\hline RSY10 ${ }^{a}$ & MATa ade2 ade6 can1-100 his3-11,15 leu2-3,112 trp1-1 ura3-1 & {$[47]$} \\
\hline RSY391 & cnc1 $1:: L E U 2$ & {$[33]$} \\
\hline RSY1006 ${ }^{a}$ & slt2 $\Delta:: h i s 5+$ & {$[26]$} \\
\hline RSY $1050^{a}$ & bck1 $1 \Delta::$ his $^{+}$ & This study \\
\hline RSY1052 ${ }^{a}$ & bck1 $1 \Delta:$ his5 ${ }^{+}$cnc1::LEU2 & This study \\
\hline RSY1736 ${ }^{a}$ & $k d x 1 \triangle:: K A N M \times 6$ & {$[28]$} \\
\hline $\operatorname{RSY} 1737^{a}$ & $k d \times 1 \Delta:: K A N M X 6$ slt2::his5+ & {$[28]$} \\
\hline RSY1988 ${ }^{a}$ & sho1 $:: K A N M X 4$ & This study \\
\hline RSY1989 & sho1 $1:$ KANMX4 bck1:: his5 ${ }^{+}$ & This study \\
\hline $\mathrm{BLY} 21^{\mathrm{b}}$ & ste $11 \Delta$ & {$[14]$} \\
\hline BLY478 ${ }^{b}$ & ste11 1 bck1::URA3 & {$[14]$} \\
\hline FLY1589 & NOP1-CFP::KANMX6 & Frank Luca personal communication \\
\hline \multicolumn{3}{|c|}{ a genotype: MATa ade2 ade6 can1-100 his3-11,15 leu2-3,112 trp1-1 ura3-1 } \\
\hline \multicolumn{3}{|c|}{ benotype: MAT $\alpha$ ade2-1 ade3-1 can1-100 his3-11,15 leu2-3,112 trp1-1 ura3-1 } \\
\hline
\end{tabular}


yeast strains RSY10 and RSY391 by using homologous recom-

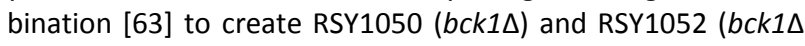

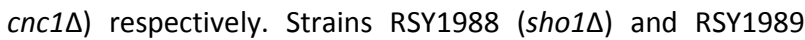
(bck1 $\Delta$ sho1 $\Delta$ ) were constructed by integrating the PCR amplified KANMX4 deleted sho1 allele, obtained from the Research Genetics deletion strain collection, into RSY10 and RSY1050 respectively. In accordance with the Mediator nomenclature unification effort [64], we will use cyclin C (SSN8/UME3/SRB11) and Cdk8 (SSN3/UME5/SRB10) gene designations, respectively. Details about the plasmids used in this study can be found in Table 2. Plasmids pKC337 (ADH1myc-cyclin C), and pBK37 (ADH1-cyclin C-YFP) are functional and have been previously described [27, 33, 34]. The initial $B C K 1-20$ construct (that was used to create pLR106) was a gift from $D$. Levin. The other constitutively activated alleles $\left(R H O 1^{G 19 V}\right.$ and $\left.P K C 1^{R 398 P}\right)$ plasmids were gifts from Y. Ohya and M. Hall, respectively. The plasmid used to visualize mitochondria (mt-DsRed) was a gift from J. Shaw. The Nop1-RFP plasmid was a gift from M. Lisby. The spo13-lacZ fusion plasmid that exhibits meiosis-specific regulation similar to that of SPO13 [65] was a gift from R. Strich.

\section{Cell growth and culturing conditions}

Cells were grown in either rich, non-selective medium (YPDA) or synthetic minimal medium (SC) to allow for plasmid selection as previously described [33]. The spo13-lacZ plate assays were conducted as previously described $[47,66]$. In short, yeast cells were grown on filter paper (3MM, Midwest Scientific) placed on agar medium selective for the plasmids. Filters were then lifted and frozen in liquid nitrogen to rupture the cells then overlayed with agar containing 5-bromo-4-chloro-3indolyl- $\beta$-D-galactopyranoside (X-Gal). After 2 to $36 \mathrm{~h}$, color development was stopped by air drying.

\section{Survival and stress assays}

For all $\mathrm{H}_{2} \mathrm{O}_{2}$ stress assays, cells were grown to mid-log phase (6 $\times 10^{6}$ cells $/ \mathrm{ml}$ ) in minimal media and then treated with $\mathrm{H}_{2} \mathrm{O}_{2}$ at the concentrations and times written. Cell survival, TUNEL and DHE assays were conducted exactly as previously described $[35,46]$. For both DHE and TUNEL assays, positive cells were detected using flow cytometry analysis $(30,000$ cells counted per time point). All statistical analysis was performed using the Student's $t$ test with $p<0.05$ considered significant. All analyses were conducted with at least three independent cultures with $\mathbf{2 0 0}$ or more cells counted per time point.

\section{Immunofluorescence microscopy and mitochondrial fission/fusion assays}

YFP-cyclin C subcellular localization was monitored and scored as described previously [28]. For all experiments, the cells were grown to mid-log $\left(5 \times 10^{6}\right.$ cells $\left./ \mathrm{ml}\right)$, treated with the concentration of $\mathrm{H}_{2} \mathrm{O}_{2}$ and for the time points indicated. The cells were harvested, fixed in $4 \%$ para-formaldehyde for 30 min, washed three times in water, stained with DAPI and then analyzed by fluorescence microscopy. Images were obtained using a Nikon microscope (model E800) with a $100 \mathrm{X}$ objective (Plan Fluor Oil, NA 1.3) and a CCD camera (Hamamatsu model C4742). Data were collected using Autoquant and processed using Image Pro software. All images of individual cells were optically sectioned $(0.2 \mu \mathrm{m}$ slices at $0.3 \mu \mathrm{m}$ spacing) and deconvolved and the slices were collapsed to visualize the entire fluorescent signal within the cell. Cyclin C-YFP foci were scored as being cytoplasmic when 3 or more foci were observed outside of the nucleus. Mitochondrial fission assays were performed on live cells as described [35]. In brief, mitochondrial fission was scored positive if no reticular mitochondria were observed that transversed half the cell diameter. Fusion was scored when cells exhibited one or more reticular mitochondria the diameter of the cell. Fission and fusion was scored for 200 cells from three independent isolates. Statistical analysis was performed using the Student's T-test with $p<0.05$ used to indicate significant differences. Live single cell imaging (Figure 4A) was accomplished by resuspending cells expressing cyclin C-YFP and Nop1-CFP in 1\% low melting point agarose, $1 \mathrm{X}$ complete minimal medium, $100 \mathrm{nM}$ MitoTracker Red CMXRos (Molecular Probes) and $0.8 \mathrm{mM} \mathrm{H}_{2} \mathrm{O}_{2}$. Images were obtained immediately and every minute starting at $30 \mathrm{~min}$. In all panels, the bar $=5 \mu \mathrm{m}$ unless otherwise stated.

\section{Western blot analysis}

Extracts prepared for analyzing myc-cyclin $\mathrm{C}$ levels were prepared from mid-log cultures $\left(6 \times 10^{6}\right.$ cells $\left./ \mathrm{ml}\right)$ as described

TABLE 2. Plasmids used in this study.

\begin{tabular}{|c|c|c|c|c|c|c|}
\hline Plasmid Name & Gene & Epitope Tag & Marker & Promotor & $2 \mu /$ CEN & Reference \\
\hline pKC337 & CNC1 & $1 \mathrm{myc}$ & TRP1 & $A D H 1$ & CEN & [33] \\
\hline pBK37 & CNC1 & YFP & TRP1 & $A D H 1$ & CEN & [27] \\
\hline pLR106 & $B C K 1-20$ & None & HIS3 & $A D H 1$ & CEN & [26] \\
\hline pY0964 & $R H O 1^{G 19 V}$ & None & URA3 & RHO1 & CEN & [39] \\
\hline PKC1* & $P K C 1^{R 398 P}$ & None & URA3 & PKC1 & $2 \mu$ & [17] \\
\hline Mt-DsRed & Mito-targeting & dsRed & TRP1 & $A D H 1$ & $2 \mu$ & [68] \\
\hline Spo13-HIS3 & spo13-LacZ & None & HIS3 & own & CEN & {$[65]$} \\
\hline Nop1-RFP & Nop1 & RFP & URA3 & own & $2 \mu$ & [69] \\
\hline
\end{tabular}


previously [33] except that the lysis buffer used was $150 \mathrm{mM}$ $\mathrm{NaCl}, 50 \mathrm{mM}$ Tris- $\mathrm{HCl} \mathrm{pH} 8.0,1 \% \mathrm{NP}-40,0.15 \%$ deoxycholic acid sodium salt, $1 \mu \mathrm{g} / \mathrm{ml}$ pepstatin, $1 \mu \mathrm{g} / \mathrm{ml}$ leupeptin, $0.2 \%$ Protease Inhibitor cocktail (Sigma). In brief, $500 \mu \mathrm{g}$ of soluble extract was immunoprecipitated using either $\alpha$-myc or $\alpha-\mathrm{HA}$ antibodies (Roche), collected on agarose $A$ beads and analyzed by Western blot. Western blot signals were detected using goat $\alpha$-mouse secondary antibodies conjugated to alkaline phosphatase (Sigma) and the CDP-Star chemiluminescence kit (Tropix). Signals were quantitated by phosphorimaging (Kodak Inc.). Half-life determinations were calculated by linear regression analysis with curves possessing $r$ values $>0.9$. Cyclin $C$ levels were standardized to Tub1 levels before comparing to other values. For Slt2 phosphorylation assays, protein extracts were made using the $\mathrm{LiOAc} / \mathrm{NaOH}$ extraction procedure exactly as described [67]. Slt2 phosphorylation was detected using $\alpha$-phospho-p44/42 antibodies (Cell Signaling) as previously described [28]. Slt2 was detected using $\alpha$-Mpk1 antibody (sc20168, Santa Cruz). Tub1 was visualized alpha-tubulin antibodies (12G10) were obtained from the Developmental Studies Hybridoma Bank (Univ. of lowa).

\section{ACKNOWLEDGMENTS}

We thank E. Elion, M. Hall, D. Levin, M. Lisby, F. Luca, Y. Ohya, J. Shaw and R. Strich for strains and plasmids. We thank $S$. Beluch for help with western analysis of sho1 bck1 strains. We also thank R. Strich for editorial help with this manuscript. This work was supported by the National Institutes of Health, USA (GM R15-113196).

\section{SUPPLEMENTAL MATERIAL}

All supplemental data for this article are available online at www.microbialcell.com.

\section{CONFLICT OF INTEREST}

The authors declare no conflict of interest.

\section{COPYRIGHT}

(C) 2015 Jin et al. This is an open-access article released under the terms of the Creative Commons Attribution (CC BY) license, which allows the unrestricted use, distribution, and reproduction in any medium, provided the original author and source are acknowledged.

Please cite this article as: Chunyan Jin, Stephen K. Kim, Stephen D. Willis and Katrina F. Cooper (2015). The MAPKKKs Ste11 and Bck1 jointly transduce the high oxidative stress signal through the cell wall integrity MAP kinase pathway. Microbial Cell 2(9): 329-342. doi: 10.15698/mic2015.09.226

12. Zalatan JG, Coyle SM, Rajan S, Sidhu SS, Lim WA (2012). Conformational control of the Ste5 scaffold protein insulates against MAP kinase misactivation. Science 337(6099): 1218-1222.

13. Zhao C, Jung US, Garrett-Engele $P$, Roe $T$, Cyert MS, Levin DE (1998). Temperature-induced expression of yeast FKS2 is under the dual control of protein kinase $\mathrm{C}$ and calcineurin. Mol Cell Biol 18(1013-1022.

14. Lee BN, Elion EA (1999). The MAPKKK Ste11 regulates vegetative growth through a kinase cascade of shared signaling components. Proc Natl Acad Sci U S A 96(22): 12679-12684.

15. Wang $X$, Sheff MA, Simpson DM, Elion EA (2011). Ste11p MEKK signals through HOG, mating, calcineurin and PKC pathways to regulate the FKS2 gene. BMC Mol Biol 12:51.

16. Jung US, Levin DE (1999). Genome-wide analysis of gene expression regulated by the yeast cell wall integrity signalling pathway. Mol Microbiol 34(5): 1049-1057.

17. Nonaka $H$, Tanaka $K$, Hirano $H$, Fujiwara $T$, Kohno $H$, Umikawa $M$, Mino A, Takai Y (1995). A downstream target of RHO1 small GTPbinding protein is $\mathrm{PKC1}$, a homolog of protein kinase $\mathrm{C}$, which leads to activation of the MAP kinase cascade in Saccharomyces cerevisiae. Embo J 14(23): 5931-5938.

8. Saito $H$ (2010). Regulation of cross-talk in yeast MAPK signaling pathways. Curr Opin Microbiol 13(6): 677-683.

9. Wu C, Whiteway M, Thomas DY, Leberer E (1995). Molecular characterization of Ste20p, a potential mitogen-activated protein or extracellular signal-regulated kinase kinase (MEK) kinase kinase from Saccharomyces cerevisiae. J Biol Chem 270(27): 15984-15992.

10. Elion EA (2001). The Ste5p scaffold. J Cell Sci 114(Pt 22): $3967-$ 3978.

11. Good MC, Zalatan JG, Lim WA (2011). Scaffold proteins: hubs for controlling the flow of cellular information. Science 332(6030): 680686.
18. Kamada Y, Qadota H, Python CP, Anraku Y, Ohya Y, Levin DE (1996). Activation of yeast protein kinase $C$ by Rho1 GTPase. J Biol Chem 271(16): 9193-9196.

19. Dodou E, Treisman R (1997). The Saccharomyces cerevisiae MADSbox transcription factor RIm1 is a target for the Mpk1 mitogenactivated protein kinase pathway. Mol Cell Biol 17(4): 1848-1859.

20. Jung US, Sobering AK, Romeo MJ, Levin DE (2002). Regulation of the yeast RIm1 transcription factor by the Mpk1 cell wall integrity MAP kinase. Mol Microbiol 46(3): 781-789. 
21. Madden K, Sheu YJ, Baetz K, Andrews B, Snyder M (1997). SBF cell cycle regulator as a target of the yeast PKC-MAP kinase pathway. Science 275(5307): 1781-1784.

22. Baetz K, Moffat J, Haynes J, Chang M, Andrews B (2001). Transcriptional coregulation by the cell integrity mitogen-activated protein kinase SIt2 and the cell cycle regulator Swi4. Mol Cell Biol 21(19): 6515-6528.

23. Kim KY, Truman AW, Levin DE (2008). Yeast Mpk1 mitogenactivated protein kinase activates transcription through Swi4/Swi6 by a noncatalytic mechanism that requires upstream signal. Mol Cell Biol 28(8): 2579-2589.

24. Truman AW, Kim KY, Levin DE (2009). Mechanism of Mpk1 mitogen-activated protein kinase binding to the Swi4 transcription factor and its regulation by a novel caffeine-induced phosphorylation. Mol Cell Biol 29(24): 6449-6461.

25. Kim KY, Truman AW, Caesar S, Schlenstedt G, Levin DE (2010). Yeast Mpk1 cell wall integrity mitogen-activated protein kinase regulates nucleocytoplasmic shuttling of the Swi6 transcriptional regulator. Mol Biol Cell 21(9): 1609-1619.

26. Krasley E, Cooper KF, Mallory MJ, Dunbrack R, Strich R (2006). Regulation of the oxidative stress response through Slt2p-dependent destruction of cyclin C in Saccharomyces cerevisiae. Genetics 172(3): 1477-1486.

27. Jin C, Parshin AV, Daly I, Strich R, Cooper KF (2013). The cell wall sensors Mtl1, Wsc1, and Mid2 are required for stress-induced nuclear to cytoplasmic translocation of cyclin $\mathrm{C}$ and programmed cell death in yeast. Oxid Med Cell Longev 2013:320823.

28. Jin C, Strich R, Cooper KF (2014). SIt2p phosphorylation induces cyclin $\mathrm{C}$ nuclear-to-cytoplasmic translocation in response to oxidative stress. Mol Biol Cell 25(8): 1396-1407.

29. Strich R, Cooper K (2014). The dual role of cyclin C connects stress regulated gene expression to mitochondrial dynamics. Microbial Cell 1(10): 318-324.

30. Ansari SA, Morse RH (2013). Mechanisms of Mediator complex action in transcriptional activation. Cell Mol Life Sci 70(15): 2743-2756.

31. Holstege FC, Jennings EG, Wyrick JJ, Lee TI, Hengartner CJ, Green MR, Golub TR, Lander ES, Young RA (1998). Dissecting the regulatory circuitry of a eukaryotic genome. Cell 95(5): 717-728.

32. van de Peppel J, Kettelarij N, van Bakel H, Kockelkorn TT, van Leenen D, Holstege FC (2005). Mediator expression profiling epistasis reveals a signal transduction pathway with antagonistic submodules and highly specific downstream targets. Mol Cell 19(4): 511-522.

33. Cooper KF, Mallory MJ, Smith JB, Strich R (1997). Stress and developmental regulation of the yeast C-type cyclin Ume3p (Srb11p/Ssn8p). EMBO J 16(15): 4665-4675.

34. Cooper KF, Scarnati MS, Krasley E, Mallory MJ, Jin C, Law MJ, Strich $R$ (2012). Oxidative-stress-induced nuclear to cytoplasmic relocalization is required for Not4-dependent cyclin $\mathrm{C}$ destruction. J Cell Sci 125(Pt 4): 1015-1026.

35. Cooper KF, Khakhina S, Kim SK, Strich R (2014). Stress-induced nuclear-to-cytoplasmic translocation of cyclin $\mathrm{C}$ promotes mitochondrial fission in yeast. Dev Cell 28(2): 161-173.

36. Wang K, Yan R, Cooper KF, Strich R (2015). Cyclin C mediates stress-induced mitochondrial fission and apoptosis. Mol Biol Cell 26(6): 1030-1043.

37. Heinisch JJ, Dupres V, Wilk S, Jendretzki A, Dufrene YF (2010). Single-molecule atomic force microscopy reveals clustering of the yeast plasma-membrane sensor Wsc1. PLoS One 5(6): e11104.
38. Philip B, Levin DE (2001). Wsc1 and Mid2 are cell surface sensors for cell wall integrity signaling that act through Rom2, a guanine nucleotide exchange factor for Rho1. Mol Cell Biol 21(1): 271-280.

39. Sekiya-Kawasaki M, Abe M, Saka A, Watanabe D, Kono K, Minemura-Asakawa M, Ishihara S, Watanabe T, Ohya Y (2002). Dissection of upstream regulatory components of the Rho1p effector, 1,3-beta-glucan synthase, in Saccharomyces cerevisiae. Genetics 162(2): 663-676.

40. Lee KS, Levin DE (1992). Dominant mutations in a gene encoding a putative protein kinase (BCK1) bypass the requirement for a Saccharomyces cerevisiae protein kinase $C$ homolog. Mol Cell Biol 12(1): 172-182.

41. Levin DE (2011). Regulation of cell wall biogenesis in Saccharomyces cerevisiae: the cell wall integrity signaling pathway. Genetics 189(4): 1145-1175.

42. Vilella F, Herrero E, Torres J, de la Torre-Ruiz MA (2005). Pkc1 and the upstream elements of the cell integrity pathway in Saccharomyces cerevisiae, Rom2 and $\mathrm{Mtl} 1$, are required for cellular responses to oxidative stress. J Biol Chem 280(10): 9149-9159.

43. Levin DE, Fields FO, Kunisawa R, Bishop JM, Thorner J (1990). A candidate protein kinase $C$ gene, $P K C 1$, is required for the $S$. cerevisiae cell cycle. Cell 62:213-224.

44. Petkova MI, Pujol-Carrion N, Arroyo J, Garcia-Cantalejo J, Angeles de la Torre-Ruiz M (2010). Mtl1 is required to activate general stress response through Tor1 and Ras2 inhibition under conditions of glucose starvation and oxidative stress. J Biol Chem 285(25): 1952119531.

45. Westermann B (2010). Mitochondrial fusion and fission in cell life and death. Nat Rev Mol Cell Biol 11(12): 872-884.

46. Khakhina S, Cooper KF, Strich R (2014). Med13p prevents mitochondrial fission and programmed cell death in yeast through nuclear retention of cyclin C. Mol Biol Cell 25(18): 2807-2816.

47. Strich R, Slater MR, Esposito RE (1989). Identification of negative regulatory genes that govern the expression of early meiotic genes in yeast. Proc. Natl. Acad. Sci. USA 86(10018-10022.

48. Bermejo C, Rodriguez E, Garcia R, Rodriguez-Pena JM, Rodriguez de la Concepcion ML, Rivas C, Arias P, Nombela C, Posas F, Arroyo J (2008). The Sequential Activation of the Yeast HOG and SLT2 Pathways Is Required for Cell Survival to Cell Wall Stress. Mol Biol Cell 19(3): 1113-1124.

49. Garcia R, Rodriguez-Pena JM, Bermejo C, Nombela C, Arroyo J (2009). The high osmotic response and cell wall integrity pathways cooperate to regulate transcriptional responses to zymolyase-induced cell wall stress in Saccharomyces cerevisiae. J Biol Chem 284(16): 10901-10911.

50. Rodriguez-Pena JM, Garcia R, Nombela C, Arroyo J (2010). The high-osmolarity glycerol (HOG) and cell wall integrity (CWI) signalling pathways interplay: a yeast dialogue between MAPK routes. Yeast 27(8): 495-502.

51. O'Rourke SM, Herskowitz I (1998). The Hog1 MAPK prevents cross talk between the HOG and pheromone response MAPK pathways in Saccharomyces cerevisiae. Genes Dev 12(18): 2874-2886.

52. Hartwell LH, Hopfield JJ, Leibler S, Murray AW (1999). From molecular to modular cell biology. Nature 402(6761 Suppl): C47-52.

53. Bilsland E, Molin C, Swaminathan S, Ramne A, Sunnerhagen $P$ (2004). Rck1 and Rck2 MAPKAP kinases and the HOG pathway are required for oxidative stress resistance. Mol Microbiol 53(6): 17431756. 
54. Wang L, Zheng W, Zhao H, Deng M (2013). Statistical analysis reveals co-expression patterns of many pairs of genes in yeast are jointly regulated by interacting loci. PLoS Genet 9(3): e1003414.

55. Cooper KF, Mallory MJ, Strich R (1999). Oxidative stress-induced destruction of the yeast C-type cyclin Ume3p requires phosphatidylinositol-specific phospholipase $C$ and the $26 \mathrm{~S}$ proteasome. Mol Cell Biol 19(5): 3338-3348.

56. Zarrinpar A, Bhattacharyya RP, Nittler MP, Lim WA (2004). Sho1 and $\mathrm{Pbs} 2$ act as coscaffolds linking components in the yeast high osmolarity MAP kinase pathway. Mol Cell 14(6): 825-832.

57. Ma Y, Qiao J, Liu W, Wan Z, Wang X, Calderone R, Li R (2008). The sho1 sensor regulates growth, morphology, and oxidant adaptation in Aspergillus fumigatus but is not essential for development of invasive pulmonary aspergillosis. Infect Immun 76(4): 1695-1701.

58. Roman E, Nombela C, Pla J (2005). The Sho1 adaptor protein links oxidative stress to morphogenesis and cell wall biosynthesis in the fungal pathogen Candida albicans. Mol Cell Biol 25(23): 10611-10627.

59. Brown AJ, Haynes K, Quinn J (2009). Nitrosative and oxidative stress responses in fungal pathogenicity. Curr Opin Microbiol 12(4): 384-391.

60. Lewinska A, Wnuk M, Grzelak A, Bartosz G (2010). Nucleolus as an oxidative stress sensor in the yeast Saccharomyces cerevisiae. Redox Rep 15(2): 87-96.

61. Mayer C, Bierhoff H, Grummt I (2005). The nucleolus as a stress sensor: JNK2 inactivates the transcription factor TIF-IA and downregulates rRNA synthesis. Genes Dev 19(8): 933-941.

62. Conaway RC, Conaway JW (2011). Function and regulation of the Mediator complex. Curr Opin Genet Dev 21(2): 225-230.
63. Longtine MS, McKenzie A, 3rd, Demarini DJ, Shah NG, Wach A, Brachat A, Philippsen $P$, Pringle JR (1998). Additional modules for versatile and economical PCR-based gene deletion and modification in Saccharomyces cerevisiae. Yeast 14(10): 953-961.

64. Bourbon HM (2008). Comparative genomics supports a deep evolutionary origin for the large, four-module transcriptional mediator complex. Nucleic Acids Res 36(12): 3993-4008.

65. Buckingham LE, Wang H-T, Elder RT, McCarroll RM, Slater MR, Esposito RE (1990). Nucleotide sequence and promoter analysis of SPO13, a meiosis-specific gene of Saccharomyces cerevisiae. Proc. Natl. Acad. Sci. 87:9406-9410.

66. Washburn BK, Esposito RE (2001). Identification of the Sin3binding site in Ume6 defines a two-step process for conversion of Ume6 from a transcriptional repressor to an activator in yeast. Mol Cell Biol 21(6): 2057-2069.

67. Zhang T, Lei J, Yang $H, X u K$, Wang $R$, Zhang Z (2011). An improved method for whole protein extraction from yeast Saccharomyces cerevisiae. Yeast 28(11): 795-798.

68. Mozdy AD, McCaffery JM, Shaw JM (2000). Dnm1p GTPasemediated mitochondrial fission is a multi-step process requiring the novel integral membrane component Fis1p. J Cell Biol 151(2): 367-380.

69. Torres-Rosell J, Sunjevaric I, De Piccoli G, Sacher M, Eckert-Boulet $\mathrm{N}$, Reid R, Jentsch S, Rothstein R, Aragon L, Lisby M (2007). The Smc5Smc6 complex and SUMO modification of Rad52 regulates recombinational repair at the ribosomal gene locus. Nat Cell Biol 9(8): 923-931. 